\title{
AS PARTEIRAS-CHEFES DA MATERNIDADE PORT-ROYAL DE PARIS NO SÉCULO XIX: OBSTETRAS ANTES DO TEMPO?
}

\author{
SCARLET BEAUVALET-BOUTOUYRIE
}

Paris IV - Sorbonne

Resumo: A Maternidade de Port-Royal, fundada em Paris em 1795, era um estabelecimentomodelo que, além do atendimento às parturientes, possuía um curso para formação de parteiras, sendo uma das poucas escolas a fornecer formação clínica às alunas. O artigo analisa os primeiros cem anos da Maternidade, destacando a atuação das parteiras-chefes como diretoras de ensino e do atendimento às parturientes. Ressalta a situação excepcional das parteiras-chefes, que conseguiram manter a ascendência sobre os parteiros apesar das críticas e da luta pelo poder por eles desencadeada, e da crescente importância que esses profissionais vinham adquirindo no panorama obstétrico e hospitalar do século XIX. Aponta para a necessidade de pesquisa em outras escolas de parteiras francesas e européias para poder avaliar o grau de originalidade dessa experiência.

Palavras-chave: Maternidade Port-Royal, parteiras-chefes, curso de parteiras, disputa entre parteiras e médicos.

Em 1795, nos antigos prédios do Oratório (Oratoire) e do convento de Port-Royal, em Paris, foi instalado o Asilo da Maternidade (Hospice de la Maternité). ' Esse novo estabelecimento substituiu o antigo Serviço das Parturientes (Office des Accouchées) do Hôtel-Dieu, instituição parisiense que remonta ao século XIV, destinada a receber mulheres em trabalho de parto e a fornecer cursos para formação de parteiras. ${ }^{2}$ Desde 1348 , na realidade, temos referências, no registro das deliberações do Hôtel-Dieu, de uma 'ventrière' des accouchées - 'cinta' para parturientes - e de uma ala especialmente reservada às mulheres que iam dar à luz. Ao mesmo tempo em que acolhia mulheres grávidas - que eram em sua maioria mães solteiras e mulheres casadas pobres, impossibilitadas de terem os filhos em casa - o Office servia de escola de formação para as futuras parteiras. A cada três meses, quatro alunas chamadas de 'aprendizes' eram formadas na arte dos partos por uma parteira-mestra.

Copyright $\odot 2002$ by Revista Estudos Feministas

' Para mais elementos, ver: BEAUVALET-BOUTOUYRIE, 1999.

2 Henriette CARRIER, 1888. 
A modernidade do Office, um dos poucos estabelecimentos a oferecer uma verdadeira formação clínica, assegurou rapidamente sua reputação não somente na França, como também no estrangeiro. No entanto, desde o fim do século XVII, mas sobretudo após o terrível incêndio que arrasou o Hôtel-Dieu em 1772, as instituições hospitalares foram alvo de enérgicas críticas, e a reforma impôs-se. Médicos e filantropos denunciaram a insalubridade dos estabelecimentos e as altas taxas de mortalidade e reclamaram por uma mudança completa no sistema hospitalar. O Office das parturientes não escapou às críticas. O cirurgião Jacques Tenon dedicou-Ihe toda uma parte (a quinta) de seu Mémoire sur les hôpitaux ${ }^{3}$ (Dissertação sobre os hospitais), e sua descrição é aterrorizante: apesar de ser estabelecimento piloto para a formação de parteiras, era também um verdadeiro leito de morte. $O$ cirurgião propôs então não somente sua reorganização, como também sua transferência. Rapidamente, o projeto foi posto em prática. Porém, o novo Hospice de la Maternité inscreve-se na continuidade do Office, e, para deixar bem marcada essa ligação, Marie Dugès, última parteira-mestra do estabelecimento, foi nomeada parteirachefe da Maternidade de Port-Royal. Ela era auxiliada por sua filha e colaboradora MarieLouise Lachapelle, que logo ocupará o cargo, em substituição à mãe. $O$ pessoal da Maternidade compunha-se de um parteiro-chefe, ${ }^{4}$ que aliás era oficialmente o diretor, de um médico e de uma parteira-chefe. Na prática, porém, era ela, em nome das funções que lhe eram destinadas, quem assumia toda a direção. Peça central da organização, a parteira-chefe manteve-se na direção da Maternidade durante todo o século XIX, período em que se identifica um aumento de poder dos parteiros e maior controle sobre as parteiras. ${ }^{5}$ Diretora dos cursos e dos cuidados às parturientes, a parteira era superior ao médicoparteiro-chefe, gozando assim de uma situação excepcional no panorama hospitalar do século XIX.

\section{A parteira-chefe diretora dos ensinamentos}

Já no Office des accouchées do Hôtel-Dieu a parteira-chefe possuía uma função e um cargo de muito prestígio. Assim, não foi por acaso que Marie-Louise Lachapelle 6 (17591812), formada por sua mãe e com quem trabalhou no Office desde a mais tenra idade, conservou a mesma superioridade quando assumiu o cargo de parteira-chefe. Viúva de um colega cirurgião, depois de quase três anos de casamento, Marie-Louise Lachapelle decidiu dedicar-se inteiramente à profissão. Ela exerceu um papel muito importante na organização da Maternidade, estabelecendo por quase um século as bases do ensino da escola de parteiras e, logo, do funcionamento do estabelecimento.

A parteira-chefe era, antes de tudo, a verdadeira diretora da escola. No curso teórico e prático, ela dava seis aulas de teoria de obstetrícia por semana às alunas, enquanto que o parteiro-chefe, apenas três. Para esse ensinamento, Marie-Louise Lachapelle aplicava um método que ela descreve em um manual destinado às alunas, ${ }^{7}$ método que as parteiras que a sucederão conservarão na íntegra. Sua pedagogia e sua maneira de ver o ensino eram muito modernas. A ciência nasce da observação - esse é o princípio fundamental

\footnotetext{
3 Jacques TENON, 1788.

${ }^{4}$ Nota da tradutora: Accoucheur, em francês, significava, então, o médico ou o cirurgião que fazia os partos. Não é feminino de parteira (sage-femme), cuja formação e atribuições eram diferentes. Posteriormente, os parteiros passaram a ser chamados de obstetras.

5 Jacques Gélis, 1988.

${ }^{6}$ Filha de Marie Josnet, última parteira do Hôtel-Dieu, e de Louis Dugès, cirurgião em Paris, ela obteve de sua mãe todos os conhecimentos teóricos e práticos relativos à arte dos partos.

${ }^{7}$ Marie-Louise LACHAPELLE, 1821.
} 
desse curso de caráter anátomo-clínico. Apoiando-se sempre na experiência, ela se esforçava para abordar as questões de maneira simples e de forma acessível às alunas, ilustrando-as com casos clínicos, a fim de permitir-lhes uma melhor assimilação da teoria. Quanto aos casos particularmente difíceis, eles eram discutidos no anfiteatro, com o uso de um manequim de demonstração. Esse método, que visava a fazer prevalecer o ensino clínico sobre o ensino teórico, foi fielmente seguido.

Além das aulas expositivas, Marie-Louise Lachapelle implantou também um sistema de repetição das aulas a fim de assegurar que as alunas adquirissem corretamente os conhecimentos. A cada ano, a melhor aluna - em geral uma aluna aprovada, que já havia freqüentado um ano de curso - era designada para repetir para suas colegas as aulas dadas pelo parteiro-chefe e pela parteira. Ela era ajudada nessa tarefa por alunas repetidoras, igualmente estudantes do segundo ano, ${ }^{8}$ que fossem boas alunas, tivessem conhecimentos sólidos e estivessem em condição de ensinar as de primeiro ano. Esse princípio da repetição inspirava-se no sistema de ensino mútuo, que propunha uma participação ativa dos alunos. Marie-Louise Lachapelle viu assim o sucesso de seu ensino, que se destinava, não nos esqueçamos, às alunas oriundas de meios modestos e que possuíam uma formação rudimentar:

Entre as alunas antigas, aquelas que têm mais facilidade para expressar-se e aptidão para aprender são encarregadas de repetir para as novas, reunidas como nas aulas práticas, os ensinamentos do professor, da parteira-chefe e da melhor aluna. Este sistema nos aproxima muito do ensino mútuo e oferece todas as suas vantagens. As repetições, é verdade, não estão livres de erros, porém estes são logo retificados pelo livro de Baudelocque que elas têm em mãos, sendo que estas mesmas repetidoras colocam muito melhor os objetos ao alcance de suas colegas, o que não pode fazer um professor falando de cima de seu estrado, para 120 alunos.

As qualidades pedagógicas de Marie-Louise Lachapelle foram reconhecidas por todos, como o mostra o elogio pronunciado pelo Barão de la Bonnardière por ocasião da entrega dos prêmios de 1822:

As numerosas alunas que ela formou são o testemunho de seu zelo e de sua capacidade. Ela sabia adaptar-se à inteligência de cada uma, de modo a tornar as aulas proveitosas para todas. Não procurava brilhar, nem se fazer admirar, ela se prendia ao que era verdadeiramente útil para formar boas parteiras; e o conseguia graças ao seu método, à sua clareza, à simplicidade de suas aulas e de seus desdobramentos, seja ao longo da teoria, seja junto do leito das enfermas.

Marie-Louise Lachapelle desejou não somente dar uma formação técnica adequada às alunas, como também transmitir-lhes a consciência de que cumpriram uma missão elevada:

\footnotetext{
${ }^{8}$ Desde a abertura da escola, consciente da insuficiência de um único ano para a formação, a administração ofereceu às alunas que o desejassem a possibilidade de repetir por mais um ano. A equipe pedagógica encoraja bastante essa prática, que se torna habitual a partir de 1815.

${ }^{9}$ LACHAPELLE, 1821.

${ }^{10}$ ARCHIVES DE L'ASSISTANCE PUBLIQUE (AAP), Procès-verbaux de distribution des prix aus élèves sages-femmes de la Maternité, Fosseyeux 678, 1822.
} 
Sejam compassivas e caridosas, sejam meigas e boas com suas enfermas (...) Não esqueçam, minhas queridas filhas, que foi junto aos pobres que vocês obtiveram seus conhecimentos. É a eles que vocês devem um ofício honrado (...) Saibam que nossas enfermas têm o duplo direito a seus cuidados porque são pobres e porque estão infelizes. ${ }^{11}$

Madeleine Legrand e Clémentine Charrier, que sucederam a Marie-Louise Lachapelle, seguiram o mesmo caminho, fazendo prevalecer a prática sobre a teoria e insistindo no papel moral da parteira. Angélique Alliot, aliás, desenvolveu particularmente esse aspecto em seu ensino. Desejando inculcar nas alunas "o sentimento da dignidade e da responsabilidade profissional e o da verdadeira caridade" 12 para com as mulheres que davam à luz na Maternidade, ela começava cada um de seus cursos por reflexões sobre a vocação de parteira e sobre as qualidades físicas e morais exigidas para o exercício da profissão. E enriquecia seus ensinamentos com conselhos de higiene aplicáveis às mulheres de todas as condições, preparando a esse respeito um sumário de terapêutica especialmente destinado à prática das alunas. A cada fim de ano, para melhor facilitar a inserção das alunas na vida profissional, ela não deixava de dar-lhes conselhos e indicações a respeito das práticas sociais e legais do ofício de parteira.

\section{QUADRO 1 -AS PARTEIRAS-CHEFES DA MATERNIDADE PORT-ROYAL NO SÉCULO XIX}

\begin{tabular}{|l|l|}
\hline Períodos de exercício & \multicolumn{1}{|c|}{ Parteiras-chefes } \\
\hline $1789-1821$ & Marie-Louise Lachapelle \\
$1822-1838$ & Madeleine -Catherine Legrand \\
$1839-1858$ & Madeleine Edmée Clémentine Charrier \\
$1858-1867$ & Adèle Angélique Alliot \\
$1867-1881$ & Charlotte Clémence Callé \\
$1881-1895$ & Félice Henry \\
\hline
\end{tabular}

Por fim, Angélique Alliot preocupou-se também com o peso da carga horária das alunas e propôs reduzir o número de aulas de parto para aumentar as repetições pelas alunas e o ensino clínico junto ao leito das parturientes. Essas propostas, que não questionavam a organização geral dos cursos, foram aceitas pela administração em 1859. Como resultado, a despeito das diminuições feitas, as jornadas das alunas continuaram muito cheias.

Porém, o papel da parteira-chefe não se limitava ao ensino; ela era também encarregada do serviço de partos.

\footnotetext{
${ }^{11}$ Discours de Marie-Louise Lachapelle à la distribution dês prix de 1819. AAP, Fossoyeux 678, 1819.

12 André CHINEAU, 1909, p. 414-416.
} 


\section{QUADRO 2 - PLANO DE ATIVIDADES DAS ALUNAS DA ESCOLA DE PORT-ROYAL EM MEADOS DO SÉCULO XIX}

\begin{tabular}{|c|c|}
\hline Horários & Plano de Atividades \\
\hline $\begin{array}{l}9 \text { h } 00 \\
10 \mathrm{~h} 00 \\
11 \mathrm{~h} 00 \\
12 \mathrm{~h} 00 \\
13 \mathrm{~h} 00 \\
15 \mathrm{~h} 00 \\
16 \mathrm{~h} 00\end{array}$ & $\begin{array}{l}\text { Levantar. Cuidados às parturientes. Visita da parteira, depois } \\
\text { do médico. } \\
\text { Missa e café da manhã. } \\
\text { Aula. } \\
\text { Batismo dos recém-nascidos. } \\
\text { Aula. } \\
\text { Almoço. Cuidados às parturientes e aos recém-nascidos. } \\
\text { Execução das prescrições. } \\
\text { Aula. } \\
\text { Repetição. } \\
\text { Aula. } \\
\text { Cuidados às parturientes. Visita da parteiras, depois do } \\
\text { médico. } \\
\text { Jantar. Execução das prescrições. } \\
\text { Oração. } \\
\text { Redação das composições sobre as aulas do dia. } \\
\text { Deitar. } \\
\text { * É preciso acrescentar a esta programação os plantões } \\
\text { noturnos. }\end{array}$ \\
\hline
\end{tabular}

\section{A parteira-chefe diretora dos cuidados}

Como responsável pelo serviço de partos, a parteira-chefe recebia as mulheres desde a sua chegada no hospital e decidia, após um exame, admiti-las ou recusá-las. A Maternidade normalmente recebia as mulheres que estavam no último mês de gravidez, mais todas aquelas que, em início ou no meio da gestação, apresentassem sinais patológicos. As recém-chegadas - uma dezena de mulheres a cada dia - eram primeiramente examinadas pela parteira-chefe e depois pelas alunas, que eram separadas em grupos de aproximadamente dez estudantes. Assim, cada aluna podia fazer o toque. As mulheres admitidas eram logo encaminhadas para as enfermarias das mulheres grávidas, onde esperavam o momento do parto. Eram confiadas a duas alunas que lhes dispensavam, sempre sob o olhar da parteira-chefe, os cuidados habituais. Desde as primeiras dores, e se a parteira detectasse o início do trabalho de parto, as mulheres eram transportadas para a sala de parto. Era ainda a parteira que, rodeada por um grupo de alunas, presidia os partos comuns. 
O regulamento estipulava, na realidade, que a parteira-chefe fosse encarregada do serviço comum dos partos. ${ }^{13}$ Além disso, nos artigos 15 e 16 do regulamento está previsto que

todas as vezes em que o parto for considerado impossível pelas únicas forças da mãe (...) a parteira-chefe operará, se não vir perigo nem para a mãe nem para a criança, nem grandes dificuldades para a execução, porém, num ou noutro caso, ela comunicará ao parteirochefe, a menos que haja um perigo mais iminente para protelar a operação. ${ }^{14}$

Esse texto estabelece uma verdadeira supremacia da parteira-chefe, que era promovida à categoria de cirurgião - ela recebia, aliás, o mesmo salário que ele, mais uma gratificação de 30 francos por aluna. Marie-Louise Lachapelle, aplicando rigorosamente os dispositivos do texto, ou mesmo em certos casos indo além deles, conseguiu impor essa superioridade da parteira sobre o parteiro, supremacia que se manterá durante quase todo o século.

É preciso dizer que a personalidade e a habilidade de Marie-Louise Lachapelle contribuíram muito para essa situação. Chaussier, nomeado médico-chefe em $1804,{ }^{15}$ davaIhe liberdade para tomar todas as decisões que ela julgasse necessárias. Baudelocque, primeiro cirurgião-chefe da casa, reconhecendo a habilidade e a competência da parteira, não receava passar-Ihe a responsabilidade de terminar os partos trabalhosos. Ele conta que gostava de vê-la operar e que aplaudia sempre seus sucessos: "A mão mais delicada, sempre conduzida pela inteligência, sabia vencer todas as dificuldades e todos os obstáculos". ${ }^{16}$ De tal modo que Marie-Louise Lachapelle era a mais alta autoridade na direção dos serviços de partos e realizava a maioria das operações normalmente reservadas aos cirurgiões: "Ela realizava então quase todas as operações obstétricas e dirigia o tratamento de diversos casos de distocia. Realizava a versão, aplicava o fórceps, fazia a redução do prolapso do cordão umbilical, colocava tampões, fazia sangria". ${ }^{17}$

As funções descritas, na verdade, iam além daquilo que normalmente se esperava das parteiras. Com efeito, a lei do 19 ventôse an XI (10 de março de 1803), sobre a reorganização do exercício da medicina, regulamentava as condições da formação e da admissão das parteiras. Estabelecia claramente que elas não podiam empregar instrumentos no caso de partos trabalhosos sem chamar um médico ou um cirurgião. Aquelas que contrariassem a lei seriam responsabilizadas pelos eventuais acidentes, e sujeitas aos tribunais. Em 1812, por uma decisão ministerial, decidiu-se limitar o material que as parteiras podiam usar a uma tesoura, uma sonda feminina, um tubo para laringe e uma cânula de injeção. Enfim, em 1825, no momento em que se discutia a reforma da lei de ventôse, volta à tona a questão dos limites do exercício profissional das parteiras, sendo então mais uma vez confirmada a proibição do uso de instrumentos. Qual não é a nossa surpresa quando vemos, no livro Pratique des accouchements (Prática dos partos), de Marie-Louise Lachapelle, o grande número de casos nos quais ela usou o fórceps, e a maneira de usálo:

Em qualquer que seja a operação relativa à arte dos partos, não encontro nenhuma posição da mulher que reúna tantas vantagens como esta que emprego diariamente na Maternidade.

\footnotetext{
${ }^{13}$ CAMUS, an $X$.

${ }^{14}$ CAMUS, an $X$.

${ }^{15}$ François Chaussier foi médico-chefe da Maternidade de 1804 a 1828.

${ }^{16}$ M. Prevost e Roman d 'Amar dir., Dictionnaire de Biographie Française, Paris, 1951-1996, articles Baudelocque et Lachapelle.

${ }^{17}$ Discurs du docteur Porak, accoucheur de la Maternité en 1904. AAP, Fosseyeux 678, 1904.
} 
Num instante, transformei a cama comum em cama de operação. Uma das bordas da cama é apoiada sobre a parede e, deste lado, acumulamos no meio travesseiros destinados a sustentar os ombros e a cabeça da mulher. $O$ sacro se apóia sobre a borda livre da cama; duas outras alunas, sentadas ao lado dos travesseiros, mantêm os ombros e seguram a mulher enquanto eu retiro a criança. (...) Em pé entre as coxas da mulher, opero da seguinte maneira (...) Lubrificar o instrumento, aquecê-lo, estas são precauções conhecidas demais para que eu me detenha aí: passo à execução (...) Jamais tento a aplicação se o instrumento precisar ser introduzido com dor. ${ }^{18}$

Depois de Marie-Louise Lachapelle, todas as parteiras da Maternidade souberam manter essa tradição de independência. É preciso dizer que os princípios em vigor na Maternidade o explicam em parte, e notadamente o fato de que os parteiros Baudelocque e Antoine Dubois, assim como seus sucessores, desde o início, esforçaram-se em fazer prevalecer os partos naturais, embora sua prática externa nem sempre corroborasse com essa escolha. Baseando-se na regra de que as parteiras não deveriam recorrer aos instrumentos, eles tentaram ensiná-las a seguir ao máximo a natureza:

Sobretudo nenhum apego (...) contem com a natureza mais do que com vocês. Mais do que operar, rezem um terço (...) Continuidade, lentidão, atenção, apalpação mesmo, eis as recomendações a serem sempre seguidas antes de fazer uso da força.

A prática confirmava largamente essa escolha, e intervenção no parto ou uso de fórceps permaneceram por muito tempo como uma exceção. Do mesmo modo, não é sem razão que as críticas aos parteiros e os primeiros questionamentos à supremacia das parteiras coincidam com o aumento do número de partos a fórceps, a partir da segunda metade do século XIX.

\section{QUADRO 3 - RELAÇÃO DOS PARTOS FEITOS NA MATERNIDADE PORT- ROYAL}

\begin{tabular}{|c|c|c|c|}
\hline Período & Total dos partos & Partos naturais (\%) & Partos não naturais (\%) \\
\hline $1797-1809$ & 17.308 & 98,7 & 1,3 \\
$1810-1839$ & 22.250 & 98,8 & 1,2 \\
$1840-1849$ & 24.544 & 98,7 & 1,3 \\
$1850-1859$ & 25.453 & 97,4 & 2,6 \\
$1860-1869$ & 15.692 & 95,5 & 4,3 \\
$1870-1879$ & 10.937 & 95,6 & 4,5 \\
\hline
\end{tabular}

\section{A parteira e o parteiro: a luta pela supremacia}

A parteira-chefe, como responsável pela admissão das parturientes e pelos partos, possuía dois registros, o de mulheres admitidas e o de partos. Fazia, todos os dias, duas

\footnotetext{
${ }^{18}$ LACHAPELLE, 1821 , tomo 1, p. 63 et ss.

${ }^{19}$ Antoine Dubois, citado por André DUPIC,1907, p. 151.
} 
visitas às gestantes e às parturientes, prescrevia o regime alimentar. Encaminhava à enfermaria aquelas que tinham necessidade de cuidados especiais e não deixava de acompanhar a visita do médico às mães enfermas. Estas duas últimas prerrogativas são totalmente exorbitantes e vê-se bem que a parteira realmente dirigia a Maternidade no lugar e na função de parteiro-chefe. Isso criou uma rivalidade entre parteira e parteiro, a ponto de provocar o desejo deste último de recuperar os poderes que normalmente the pertenciam. O conflito surgido entre Paul Dubois e Madeleine Legrand ilustra perfeitamente essa rivalidade.

Em 1825, Paul Dubois sucedeu a seu pai Antoine como parteiro-chefe da Maternidade. Um violento conflito o colocou contra Madeleine Legrand, parteira-chefe desde 1822. A disputa, que rapidamente se degenerou em uma grande contenda, irrompeu a propósito da delimitação sobre a competência da parteira e do parteiro-chefe. ${ }^{20}$ Madeleine Legrand era uma antiga aluna da Escola. Premiada na admissão de 18091810 , foi aluna de Marie-Louise Lachapelle e distinguiu-se por suas qualidades, obteve 0 primeiro prêmio de estímulo e de vigilância clínica, e o segundo de obstetrícia. Estabelecida como parteira em Versalhes, em 1822, sucedeu a Marie-Louise Lachapelle, não abandonando os princípios adotados pela antecessora. Esta justamente implantou um registro das observações, executado pela parteira-chefe, no qual anotava cada parto. Tratava-se de uma ficha com observações sobre as condições clínicas da gestante na admissão, sobre o trabalho de parto e do pós-parto, e sobre o recém-nascido. Ao ingressar como parteiro-chefe na Maternidade, Paul Dubois decidiu começar um registro do mesmo tipo, propondo, entretanto, a Madeleine Legrand de fazerem isso em conjunto. Ela aceitou com reservas, pois percebeu nesse ato a vontade de Dubois de se apoderar da direção da Maternidade. O conflito eclodiu no final do mês de setembro de 1825 , quando ela constatou que Paul Dubois dirigiu-se, sem informá-la, à sala de admissão das mulheres. Ela escreveu a esse respeito:

Continuando o sistema de invasão que (Dubois) adotou, ele se dirigiu em 27 de setembro à sala de admissão das gestantes e lá, coisa que não acontecera jamais até este dia, na presença das alunas-parteiras de plantão, ele fez o toque das mulheres grávidas que aguardavam, tomou notas sobre o resultado de seu exame, tudo sem a presença da parteirachefe e sem ter-lhe dado a mínima informação de suas intenções a esse respeito.

A partir daí, as ocasiões de atrito entre Madeleine Legrand e Dubois se multiplicaram. Alguns dias depois do ocorrido, Madeleine Legrand, advertida por uma aluna, chegou à sala de parto e encontrou Dubois e um interno de medicina realizando o parto de uma mulher. Magoada por não ter sido prevenida - o regulamento estipulava que o parteiro só podia entrar na sala de trabalho de parto quando chamado pela parteira -, Madeleine Legrand protestou e o repreendeu abertamente, bem como redigiu uma recriminação no relatório. Encaminhou imediatamente uma nota ao diretor da Maternidade, desenvolvendo toda uma argumentação para defender sua posição no interior da instituição. Começou por evocar a repugnância das mulheres em serem examinadas por um homem e o risco de privar as alunas dessa fonte de instrução:

Desde sempre as mulheres grávidas só se submetem a essa visita com enorme repugnância (...) Muitas preferiram mesmo ir embora e privar-se dos socorros do hospital, a aceitá-la (...) Elas reclamam, dizem-se inquietas por terem sido submetidas aos exames de um homem. É

\footnotetext{
${ }^{20}$ A disputa é relatada por Madeleine Legrand em uma nota de 1825, nota essa citada integralmente por Paul BAR, 1908, p. 23-31.

${ }^{21}$ BAR, 1908, p. 31.
} 
certo que se se permitisse ao Senhor Paul Dubois fazer essa operação, as alunas ver-se-iam logo totalmente privadas dessa fonte de instrução tão necessária ao exercício de sua função. ${ }^{22}$

Evidentemente, por trás dessa argumentação percebe-se a preocupação em conservar a direção da Maternidade. Em seguida, ela salienta que o regulamento não definia com suficiente precisão as atribuições respectivas da parteira-chefe e do médicoparteiro e acusa o jovem Dubois de aproveitar-se dessa imprecisão:

Este jovem professor parece animado por um espírito de inovação, próprio da idade, impresso em seus olhos pelo desejo de promover progressos científicos e ampliar a instrução das alunas. Porém, corre-se muitas vezes o risco de estragar o que vai bem querendo obter o melhor; receio que as tentativas que realizou possam ser louváveis mais como sinal de boa intenção do que de reflexão madura (...) Uma escola destinada a instruir mulheres não pode ser dirigida, neste momento, senão por uma outra mulher. ${ }^{23}$ BAR, 1908, p. 31.

A necessidade de reservar a escola somente às alunas mulheres e dela excluir os alunos cirurgiões ou médicos já havia sido defendida por Marie-Louise Lachapelle, por ocasião da sua criação. Madeleine Legrand acrescenta aí a exclusividade da direção feminina.

De um ponto de vista concreto, ela reivindicava para si o direito de visitar as mulheres na sala de admissão, de realizar ela mesma, com as alunas, os partos naturais ou os que não apresentassem complicações graves, de ser o único juiz a decidir quando chamar o parteiro-chefe e, por fim, de fazer os registros clínicos de admissão e de parto. Entretanto, ela se dizia à disposição do parteiro para informar sobre os registros clínicos quando ele desejasse. Essa questão da elaboração dos registros é fundamental, Madeleine Legrand tem consciência disso:

Um registro efetuado na sala de parto pelo parteiro-chefe necessita de sua presença quase permanente (...) Ele preside tudo e domina tudo. Se a parteira não aceitar submeter-se às suas ordens, torna-se fraca. Não goza mais da consideração que torna fácil a obediência e perde logo toda a influência, toda a autoridade sobre suas alunas, que não pode mais dirigir. ${ }^{24}$

A discussão foi mais longe. A parteira não receou contestar o parteiro no que diz respeito às prerrogativas técnicas e ao ensino. A tentativa de Dubois de questionar a supremacia da parteira-chefe fracassou e não teve continuidade. Madeleine Charrier, e sobretudo Angélique Alliot, que sucederam a Madeleine Legrand, terão o cuidado de preservar a posição e de manter a primazia. Entretanto, ao longo dos anos, a posição de parteira-chefe parece cada vez mais contestada. Em 1866, a Sociedade de Cirurgia se mostrava admirada dessa independência, e o doutor Léon La Fort denunciava o fato, que considerava único na Europa:

Não é lamentável a situação de ver a parteira-chefe sozinha encarregada, senão de direito ao menos de fato, o que é bem pior, da direção do serviço das parturientes sadias? (...) A parteira-chefe, e é disso que temos o direito de muito nos admirar, é independente do cirurgiãochefe, em seu serviço. Na prática, o cirurgião só vem ao serviço da parteira quando é chamado por ela. Essa independência da parteira encarregada de um serviço não existe no exterior.

\footnotetext{
22 BAR, 1908, p. 31.

${ }^{24}$ BAR, 1908, p. 31.

${ }^{25}$ LE FORT, 1866, p. 207.
} 
Esse gênero de crítica não é completamente novo - Sacombe, rival de Baudelocque, já tinha, em 1802, dirigido virulentas críticas ao funcionamento do estabelecimento, especialmente pela "mais bela escola do mundo estar confiada a uma mulher" 26 - mas demonstra que a partir de então não se tolerava mais que uma parteira pudesse desempenhar o papel de um cirurgião. Na realidade, na Maternidade, os poderes da parteira-chefe serão cada vez mais limitados, e, no fim do século XIX, não se cogitava mais confiar-lhe, como nos tempos de Baudelocque e dos Dubois, o cuidado dos partos difíceis. Em 1860, os parteiros começaram a retomar o papel que era considerado naturalmente deles, e o aumento do número de partos por fórceps (de 1,2\% para 4,5\%, ver quadro 3) traduz bem a mudança no estado de espírito.

\section{QUADRO 4 - OS PARTEIROS-CHEFES DA MATERNIDADE PORT-ROYAL}

\begin{tabular}{|c|l|}
\hline Período de exercício & Parteiros-chefes \\
\hline $1802-1810$ & Jean-Louis Baudelocque \\
$1810-1825$ & Antoine Dubois \\
$1825-1856$ & Paul Antoine Dubois \\
$1857-1864$ & Antoine Constant Danyau \\
$1864-1867$ & Ulisse Trélat \\
$1867-1889$ & Stéphane Tarnier \\
\hline
\end{tabular}

As disposições legislativas, como se vê no decreto de 18 de novembro de 1881 , só reforçaram tal mudança. Com essa medida, uma nova ordem de profissionais foi criada, a dos parteiros dos hospitais, que, recrutados por concurso, ficaram a partir de então na direção dos serviços de partos. Gozando de grande prestígio, eles assumiram a direção, e as parteiras foram rebaixadas a suas auxiliares. Na Maternidade Port-Royal, entretanto, foi preciso esperar ainda o decreto de 31 de maio de 1895 para que a parteira-chefe visse oficialmente seus poderes restringidos e fosse definitivamente colocada sob às ordens do parteiro. Essa disposição marcou verdadeiramente o fim de uma época. A partir de então, foi apenas na prática privada e nos partos naturais que as parteiras conservaram sua supremacia, ao menos até a segunda metade do século $X X$, época na qual o parto hospitalar substituiu o parto domiciliar.

Durante todo o século XIX, as parteiras-chefes de Port-Royal conseguiram manter sua ascendência sobre o parteiro. Verdadeiras diretoras do estabelecimento, elas contribuíram para dar às alunas uma formação de qualidade e firmaram-se como verdadeiras cirurgiãs. Essa situação, totalmente surpreendente no que diz respeito à legislação, não era esperada quando da abertura da Maternidade, visto existirem todas as condições desde o fim do século XVIII para que os parteiros suplantassem comadres e parteiras. ${ }^{27}$ Como explicar que em Port-Royal as coisas tenham-se desenrolado dessa maneira? Sem dúvida, diversos elementos entraram em jogo, e com certeza em primeiro

\footnotetext{
${ }^{26}$ Sobre a disputa entre Sacombe e Baudelocque, ver: Bernard THIS, 1982, p. 202 et ss.

27 Sobre esta rivalidade, ver: GÉlis, 1988.
} 
lugar a origem da supremacia da parteira-chefe se deve à forte personalidade de MarieLouise Lachapelle; as mulheres que a sucederam só precisaram dar continuidade à sua obra. O acúmulo de atribuições dos parteiros da Maternidade, que eram, ao mesmo tempo, professores de faculdade, clínicos na cidade e responsáveis pelo hospital, contribuiu sem dúvida para o seu relativo afastamento. Enfim, se no século XVIII a cirurgia e notadamente a obstetrícia puderam ser consideradas como um meio de promoção profissional e social, o sucesso obtido fez com que os parteiros, menos apegados à sua posição, deixassem mais campo livre às parteiras; e seria somente a sua promoção à categoria de parteiros dos hospitais, no fim do século XIX, que poderia explicar uma mudança nessa situação.

Resta uma última questão: a Maternidade Port-Royal constitui um caso isolado ou, ao contrário, é representativa de um modelo? Somente uma comparação com outras escolas, como as de Strasbourg, Lyon, Bordeaux ou Montpellier, e, mais ainda, com estabelecimentos europeus poderia permitir concluir e melhor ressaltar a originalidade dessa experiência.

\title{
Referências bibliográficas
}

BAR, Paul. Pierre Budin : la chaire de clinique obstétricale à la Faculté de médecine de Paris, Paris, 1908. Aula inaugural proferida em 7 de janeiro de 1908.

BEAUVALET-BOUTOUYRIE, Scarlet. Naître à l'hôpital au XIXe siècle, Paris, Belin, 1999.

CAMUS. Code spécial de la Maternité, an X.

CARRIER, Henriette. Les origines de la Maternité de Paris. Les maîtresses sages-femmes et l'Office des accouchées de l'ancien Hôtel-Dieu, Paris, 1888.

CHINEAU, André. Biographie de Madame Alliot, sage-femme en chef de la Maternité de Paris, La France Médicale, 1909.

DUPIC, André. Antoine Dubois. Chirurgien et accoucheur, Tese de medicina, Paris, 1907.

GÉLIS, Jacques. La sage-femme ou le médecin. Une nouvelle conception de la vie, Paris, Fayard, 1988.

LACHAPELLE, Marie-Louise. Pratique des accouchements, ou mémoires et observations choisies sur les points les plus importants de l'art, Paris, 1821, 3 tomos.

LE FORT, Léon. "De I'hygiène des maternités", Bulletins de la Société de chirurgie, 1866.

TENON, Jacques. Mémoire sur les hôpitaux, Paris, 1788.

THIS, Bernard. La requête des enfants à naître, Paris, Seuil, 1982.

Tradução de Maria Helena Gallotti

\begin{abstract}
The Head-Midwives of the Port-Royal Maternity in Nineteenth-Century Paris: Obstetricians before their Time?

Abstract: The Maternity of Port-Royal, founded in Paris in 1795, was a model establishment which, besides specializing in childbirth, functioned as a school for midwives, being one of the few that provided clinical instruction. This article analyzes the first hundred years of the Maternity, showing the work of head-midwives as authorities both in teaching and in the care of patients. It emphasizes the special status of the head-midwives, who managed to maintain power over medical obstetricians in spite of their criticism and struggle for dominance, and of the growing importance of the latter in 19th-century medical and hospital organization. The analysis points to the need for further research about other French and European schools in order to better evaluate the experience of midwifery in those times.
\end{abstract}

Key words: the Port-Royal Maternity, head-midwives, school for midwives, dispute between midwives and doctors. 